\title{
Review of Research on the Studies of the Popularization of Marxism in Recent Ten Years
}

\author{
Ying Wang \\ Zhejiang University, China Zhejiang Hangzhou 310007 \\ wing8939@126.com
}

Keywords: the Popularization of Marxism, the basic domain, main features.

\begin{abstract}
Advancing the popularization of Marxism in contemporary China is a major task of the study of Marxist theory in the present and future years. Since the proposition of 'Popularization of Marxism' was formally put forward in the report of the 17th National Congress of the CPC in 2007, the academic circles have carried out extensive basic research on the theoretical basis, scientific connotation, developing history and realization path of the popularization of Marxism. In the past ten years, the study of the popularization of Marxism has experienced the transformation from the response of basic theory to the specific practice. Significant progress has been made on the study of Marxist theorists, the CPC and the popularization of Marxism. The research on the popularization of Marxism in specific groups, periods and areas is gradually expanding.
\end{abstract}

\section{Introduction}

Promoting the popularization of Marxism is an important measure to strengthen the leading position of Marxism in the field of Chinese ideology. The first explicit 'Promoting the Popularization of Marxism in Contemporary China' in the report of the 17th National Congress of the Communist Party of China is an important theoretical proposition and strategic task based on the accurate judgment of the situation of ideological struggle in the international and domestic states. In the current ideological field, the struggle is fierce and there are many problems, and various social ideological trends collide with each other, which poses a severe challenge and impact to the mainstream ideology of Chinese Marxism. Advancing the popularization of Marxism in contemporary China is a major task of the study of Marxist theory in the present and future years.

Since the proposition of "Popularization of Marxism" was formally put forward in 2007, the academic circles have carried out extensive basic research on the theoretical basis, scientific connotation, developing history and realization path of the popularization of Marxism. In the past ten years, the research perspective of the popularization of Marxist theory has been expanding, and new research growth has been emerging.

\section{The basic domain of research}

The idea of popularization of Marxism has a long history, but after the explicit definition of the 17th National Congress of CPC, the relevant research of this concept has been strengthened obviously, which has caused the theoretical circle to pay great attention to the study of the relationship between the Marxism popularization and Marxism sinicization and Marxism modernization. The basis, history, content, object, path and method of the popularization of Marxism are also studied in depth. The official attention and the academic response make the popularization of Marxism much concerned. The basic discourse of the current study of Marxism popularization mainly involves the following aspects.

\subsection{The scientific connotation and necessity is the starting point on the study of the popularization of Marxism}

The connotation of the popularization of Marxism has not yet been clearly defined, the 
theoretical circles mainly have the following several representative views. First, it is thought that the popularization of Marxism means the process of the basic principles of Marxism from abstract to concrete, from profound to popular, and from being understood by the minority to be grasped by the masses [1]. The second view holds that the proposition of the popularization of Marxism in contemporary China has two meanings. From the former, it refers to the popularization of the Marxist theory of contemporary China, that is, the theoretical system of socialism with Chinese characteristics. From the latter, it refers to the popularization of Marxism in the contemporary Chinese conditions, including the popularization of the basic Marxist theory, but also the popularization of the theoretical achievements of Marxism sinicization [2]. Some scholars believe that the popularization of Marxism is the popularization of Marxism in contemporary China, which is composed of three phrases: contemporary China, Marxism and popularization, and can be interpreted by three-level meaning. The first meaning: popularize contemporary Chinese Marxism to the masses. The second meaning: the popularization of contemporary Chinese Marxism. The third meaning: Marxism popularization of contemporary China [3]. The popularization of Marxism in contemporary China is under a new and more complex reality and historical conditions. It is a new-era topic, should undertake new tasks. Scholars generally believe that promoting the popularization of contemporary Chinese Marxism is the need to deal with the current diversified social ideological trend, to consolidate the socialist ideology, and to enrich and develop Marxism, which is the inevitable requirement of the development of the times and the cause of socialism with Chinese characteristics.

\subsection{The relationship between the popularization of Marxism and the sinicization and modernization of Marxism is the hot point on the study of the popularization of Marxism}

A common view is that the sinicization, modernization and popularization of Marxism are not only different from each other, but also interrelated and promoted. As some scholars put forward, the proposition of sinicization is connected with the concept of space, and the proposition of modernization is connected with the concept of time, and the concept of popularization is related to the concept of value goal [4]. There is also a view that the sinicization of Marxism is embedded with the modernization and popularization. Marxism is a scientific theory from practice and guiding practice, and the people are the main body of social practice, so the process of sinicization of Marxism must be accompanied by the process of popularization of Marxism [5]. Another point of view is that the sinicization, modernization and popularization of Marxism is a whole, they are interrelated and integrated. In this whole, sinicization is the theme part [6].

\subsection{The realization path of Marxism popularization is the focus on the study of Marxism popularization}

To realize the popularization of Marxism, the key is to solve the problem of path and method. Therefore, the research on the realization path of Marxism popularization is also the most concentrated. Indoctrination is still the basic method and the main way to promote the popularization of Marxism [7]. But in the new era, more emphasis should be laid on innovation, instilling methods and enhancing the effect of indoctrination. And to protect and improve people's livelihood, promoting social harmony and progress is also the most direct and effective way to achieve the popularization of contemporary Marxism. Some scholars also discussed the ideological and political education path of the popularization of Marxism. The effective realization path of contemporary Chinese Marxism popularization, including text path, organization path and propagation path are also discussed and summarized [8]. And there are other scholars proposed to diversify the means of communication and build a multi-level, diversity and multi-channel, three-dimensional modern theoretical dissemination system by widening the original position of propaganda and education, and boldly drawing on the theoretical and practical experience of modern communication such as literature dissemination, cultural dissemination, news dissemination, film and television communication [9]. On the study of the ways and means of popularization of Marxism, scholars have generally stressed the need to reflect on the traditional Marxist mode of 
communication, change the way of thinking, and comprehensively use various kinds of communication media and carrier to promote the theory of propaganda and education.

\section{Main features of the study}

Since 'the Popularization of Marxism' was put forward in 2007, the related research on this topic has shown the following characteristics in the past ten years.

\subsection{From the response of basic theory to the specific practice}

The academic circles have reached a consensus on the basic issues of the connotation, basis, necessity and possibility of the popularization of Marxism. The study of the popularization of Marxism has been further deepened, especially the study on how to promote the popularization of the specific ways, showing a trend of further deepening and refining. The study of the popularization of Marxism has begun to pay more attention to specific practice, focusing on the combination of theory and practice. There are many new opinions on the traditional field of Marxism popularization, and the efforts to excavate the Marxist theoretical resources in combination with the social reality are in the ascendant. Because the Chinese reality is fluctuant, the theoretical understanding of the theory is not static, the combination of theory and practice is in the development of changes, the combination of theory and practice is constantly innovative, so the theory of Marxism and the actual combination of the theoretical results will be more, this aspect of course will follow the principle of keeping pace with the times.

\subsection{Significant progress has been made on the study of Marxist theorists, the Communist Party of China and the popularization of Marxism}

Marxist theorists, revolutionaries, and leaders of the party, as historical figures with special influence, have special qualities and special status, so that they can embody and represent the group of Marxist theorists, the innovative ability and wisdom of the masses, and play a representative role in the process of Marxism popularization. With the deepening of research, the research focus is to summarize the historical achievements or influence of the relevant subjects on the popularization of Marxism. Among them, Zedong Mao as a great pioneer to realize the sinicization of Marxism and make theoretical creation, the theoretical circle has the most focus on the research of Zedong Mao and the popularization of Marxism, and the results are most abundant. There is also the study of Marxism popularization thought of Marx, Engels, Lenin and other Marxist theorists, and the research on the leadership of the communist party of China and the popularization of Marxism.

\subsection{The research on the popularization of Marxism in specific groups, periods and areas is gradually expanding}

Specific groups are mainly concentrated in intellectuals, revolutionaries and young people. Such as the study of intellectuals and the popularization of Marxism in Yan' an period, the study of Hunan proletarian revolutionaries and Marxism popularization, and research on the problem of youth groups and the popularization of Marxism. Based on a large number of original historical materials, the research results of the popularization process of Marxism in specific regions in a given period are increased year by year, such as the study of Marxism popularization in the period of the May 4th Movement, the Central Soviet area, the Yan' an period, the Anti-Japanese War period, the initial stage of the New China, Tibet, Xinjiang and the ethnic region.

The study of the popularization of Marxism in the theoretical circle has shown a relatively prosperous situation. The academic circle has carried out the research from multi-domain, multi-angle, multi-discipline, multi-level, obtained a series of important theoretical achievements, providing the research foundation and practical guidance for further research. But there are still many problems in the research and practice of Marxism popularization, for example, there are not many researches on the rationality and practicality of Marxism; the research areas of historical experience and lessons need to be further expanded; the study of 'The Public' needs to be further 
refined, differentiated and deepened.

The popularization of Marxism is not a one-way communication process from the existing theory to the established mass. The popularization itself is a feedback process to review Marxism, test Marxism and develop Marxism. Therefore, the popularization of Marxism is difficult and arduous, and must be fully understood and grasped. The study of the popularization of Marxism needs to dig, sort out and summarize the relevant historical data, summarize the present fresh experience, extract the essence in practice and promote it in the appropriate scope, study on the theoretical connotation, and make a convincing theoretical answer to a series of important theoretical issues of concern to the public.

\section{References}

[1] Renquan Lu, Baoqing Yang. Three discussions on the popularization of Marxism [J]. Research on Ideological and Political Work, 2008 (6) 7-9.

[2] Jianjun Liu. Some issues on the popularization of Marxism in contemporary China [J]. Ideological \& Theoretical Education, 2008 (7) 25-30.

[3] Guomin Xu. Doctrine and problem: theoretical analysis of the popularization of Marxism in contemporary China [J]. Lanzhou Academic Journal, 2008 (8) 24-27.

[4] Yaping Wang, Yan Sun. A summary of the academic symposium on the sinicization, modernization, popularization and Marxist theoretical innovation [J]. Ideological \& Theoretical Education, 2010 (13) 94-95.

[5] Yiting He. Promoting the sinicization, modernization and popularization of Marxism [N]. People's Daily, 2009-10-27.

[6] Jianning Guo. The sinicization, modernization and popularization of Marxism [N]. Beijing Daily, 2010-01-17.

[7] Yongguang Zhang. Indoctrination theory and popularization of Marxism: On the understanding of the scientific development outlook of the deep learning practice $[\mathrm{J}]$. Theoretical Horizon, 2010 (3) 31-33.

[8] Ran Li, Reflection on the route to the popularization of Marxism in contemporary China [J]. Studies on Mao Zedong and Deng Xiaoping Theories, 2009 (7) 7-11.

[9] Qian Yang, Wensheng Yang. The basic experience of the popularization of Marxism in contemporary China [J]. Marxism \& Reality, 2010 (4) 191-194. 